\title{
Using Bronfenbrenner's Ecological Approach to Understand Academic Advising with International Community College Students
}

\author{
Yi Leaf Zhang \\ The University of Texas at Arlington, USA
}

\begin{abstract}
This study focuses on advising international students in a Texas community college. Guided by Bronfenbrenner's ecological model, I explored how academic advising with international students was shaped by individual backgrounds and environmental influences. I utilized a qualitative research design and analyzed information collected from interviews with 20 academic advisors and 15 international students at the community college. The findings of the study revealed factors in each subsystem of the model that may exert an important impact on international students' experiences in advising and academic success. The findings can provide a valuable lens for advisors to better understand the challenges of working with international students and unveil forthcoming experiences for prospective international students.
\end{abstract}

Keywords: academic advising, community college, ecological model, international students, qualitative research

Evolving from routine activities, academic advising has become an integral part of U.S. higher education (Campbell \& Nutt, 2008). It is a significant component of college experiences for all students, especially for those who are unfamiliar with college processes and policies (Swecker, Fifolt, \& Searby, 2013). Numerous researchers have demonstrated that effective advising contributes to students' engagement, satisfaction, loyalty, and important learning outcomes, such as cognitive development, academic performance, retention, and graduation (e.g., Bai \& Pan, 2009; Campbell \& Nutt, 2008; Hunter \& White, 2004; Kim, Collins, Rennick, \& Edens, 2017; Mamiseishvili, 2012; Vianden \& Barlow, 2015). Unfortunately, international students, who often undergo a series of challenges due to differences in language, culture, and former education (Bista, 2015), may not fully understand the role of academic advisors in U.S. higher education, and consequently, fail to capitalize this critical resource for academic success (Lau, Garza, \& Garcia, 2018; Mori, 2000; Nazarenko, 2006). In addition, academic advisors experience challenges in efficiently engaging international advisees. Advisors may be aware of the difficulties faced by international students but are not equipped with adequate knowledge in conducting effective advising with international students (Zhang \& Dinh, 2017). 
Despite the challenges that both international students and academic advisors encounter, U.S. colleges and universities continue to attract the most substantial number of international students in the world (Institute of International Education [IIE], 2017a). In the 2015/16 academic year, a new record of 1,043,839 international students enrolled in U.S. higher education institutions, which was a $7.1 \%$ increase from the previous year and represented $5.2 \%$ of total college enrollment in the U.S. (IIE, 2017b). Serving such a large number of international students, U.S. higher education educators, practitioners, and administrators need to reevaluate academic services provided for international students and to develop a more nuanced understanding of their experiences on U.S. campuses, especially in academic advising. Researchers (Charles \& Stewart, 1991; Gillespie, 2012; Rice et al., 2009; Zhai, 2004) have attempted to provide more knowledge in advising international students, but most of the efforts are dedicated to students in four-year universities, although community colleges have become an essential destination for many international students. Indeed, in the 2015/16 academic year, almost one fifth $(18.3 \%)$ of the entire international undergraduate population were at the associate's level, and it increased by $12.6 \%$ from $2014 / 15$, which was the highest rate at all academic levels (IIE, 2016).

Therefore, in the current study, I focus on international community college students and intend to provide a more holistic understanding of academic advising in a cross-cultural environment. Specifically, I took an ecological approach to investigate how international student academic advisement in a community college was shaped by the individual experiences of both advisors and advisees and environmental influences at various levels.

\section{THEORETICAL FRAMEWORK AND RELEVANT LITERATURE}

I adopted Bronfenbrenner's $(1977,1979,1992)$ ecological model to guide the study. This ecological approach does not only allow researchers, educators, and practitioners to understand experiences of individual students in academic advising, but also help them gain in-depth insight into how to create a campus environment that can enhance student development. The ecological model consists of five systems of interaction that the former is nested in the latter: 1) Microsystem, 2) Mesosystem, 3) Exosystem, 4) Macrosystem, and 5) Chronosystem. Since it was developed four decades ago, Bronfenbrenner's model has been applied in various fields of study, such as Children's mental health (McLeod \& Shanahan, 1993), pediatric injury (Schwebel \& Brezausek, 2007), suicidal ideation (Langhinrichsen-Rohling, Snarr, Slep, Heyman, \& Foran, 2011), and identities of mixed-race college students (Renn, 2003). It has also been employed to conceptualize the consulting training environment ( $\mathrm{Lau} \& \mathrm{Ng}, 2014$ ) and working with immigrant students (Paat, 2013; Stebleton, 2011). This model has not been applied to studying advising international students in a community college context. Given the importance and complexity of advising, this model would allow academic advisors in community colleges to obtain a better understanding of individual and contextual factors that influence international student advisement.

\section{Microsystem}

The most inner circle, microsystem, is a "pattern of activities, roles, and interpersonal relations experienced by the developing person in a given setting with particular physical and material characteristics" (Bronfenbrenner, 1979, p. 22). In academic advising, the most important individuals that international community college students interact with are academic advisors. International students view academic advising as an important service on campus and 
regard it as a positive influence on their studies and college transition (Cadieux \& Wehrly, 1986; Charles \& Stewart, 1991; Tas, 2013). However, international students do not receive adequate advising from the international office and advisors (Nazarenko, 2006). Specifically, Asian and Latin American students are concerned that their adjustment and academic studies are not sufficiently addressed by their advisors (Nazarenko, 2006). When compared to their domestic counterparts, international students tend to be less satisfied with their advising experience (Kim et al., 2017; Kim, Edens, Iorio, Curtis, \& Romero, 2015).

In addition, advising and counseling services are often underutilized among international students (Mori, 2000). Mamiseishvili (2012) indicates that one of every five (20.3\%) international students in four-year universities never met with their advisors during the first year and the percentage was almost doubled (39.6\%) for international students in community colleges. According to data drawn from the Community College Survey of Student Engagement (CCSSE), more than one-fifth (21.7\%) of international community college students rarely or never consulted with an academic advisor, and $6.2 \%$ were unaware of the academic advising service at all (Lau et al., 2018).

\section{Mesosystem}

A mesosystem is defined as a collection of microsystems and how these systems interact with each other (Bronfenbrenner, 1977). For international community college students, the mesosystem comprises interactions with not only academic advisors, but also parents, friends, faculty, staff, and other student affairs professionals. Each interaction forms a microsystem, and a collection of these interactions create a mesosystem.

In the mesosystem, interactions with parents and friends play a critical role in international students' support network and can exert important impacts on the students' college experiences. Although most of them are studying alone in the U.S., international students still view their parents and friends at home as top resources of support and turn to them for help and advice. An early study (Leong \& Sedlacek, 1986) notes that international students tend to seek help from parents, older friends, or other students when they have emotional or social problems, while when they have study- or career-related questions, they are more likely to consult faculty advisors, parents, and older friends. A recent study by Bhochhibhoya, Dong, and Branscum (2017) asserts that international students mostly rely on their family and friends in the home country for social support. They also like to seek help from people who live in the U.S. but came from the same home country. Baloglu (2000) suggests that friends are the most favorable source of support for international students, followed by parents and faculty.

\section{Exosystem}

Extending outward to the next level, the exosystem includes "other specific social structures, both formal and informal, that do not themselves contain the developing person but impinge upon or encompass the immediate settings in which that person is found, and thereby influence" (Bronfenbrenner, 1977, p. 515). For international students studying in U.S. community colleges, influential structures in the exosystem may include U.S. foreign policies, immigration laws, visa regulations, and academic requirements for international students.

The visa-screening process in the wake of the September 11 terrorist attacks became more constricted for international students and scholars, especially those from the Muslim-majority countries (Kless, 2004). The increased scrutiny led to severe delays in visa issuances and mandated additional reviews on students who applied for educational programs in sensitive fields, such as biochemistry, navigation engineering, and nuclear physics (Burd, 2002). Not 
surprisingly, there was an immediate decline in the international student enrollment in the U.S. in the following few years (IIE, 2017b). A recent example of the political impact on international student enrollment and experiences is Trump administration's anti-immigrant policies. Although it might still be too early to see the full picture of the effect on international education, some campuses have seen a decrease in their international applicants and enrollment (Fischer, 2017). The policies also caused confusion, stress, and even fears among international students who are currently enrolled in the U.S. colleges and universities (Rose-Redwood \& Rose-Redwood, 2017). As a result, academic advisors and other educational practitioners may experience more challenges when working with international students.

To maintain their legal student status, international undergraduate students are required to complete at least 12 credit hours per semester. Although part-time enrollment is allowed, the students need to receive permission from the international services office, and it is only applied to special occasions. For instance, at the community college where the research was conducted, international students who are in the last semester before graduation and need fewer credit hours to graduate are allowed to enroll as part-time students. Additionally, students with illness or medical conditions that prevent them from enrolling in full-time are allowed to take fewer than 12 credit hours per semester. This policy has placed enormous pressure on international students because failing or dropping a course can cause a violation of their visa policy, which may lead to deportation. It also makes advising international students more complicated. International students need to consult international services officers as well as academic advisors before deciding to drop a class or changing academic plans (Bargerstock \& McCarthy, 2012).

\section{Macrosystem}

The macrosystem represents the broader level and is the layer of the ecological system that is furthest from the center (i.e., the student). According to Bronfenbrenner (1977), macrosystem is "the overarching institutional patterns of the culture or subculture, such as the economic, social, educational, legal, and political systems, of which micro-, meso-, and exo-systems are the concrete manifestations" (p. 515). Although it may seem distant from the students and their interactions with academic advisors, a wide variety of structures in the macrosystem can potentially affect international students' experiences. In a study of immigrants, Stebleton (2011) notes that students' advising could be influenced by various factors at the macro level, including higher education cultures in the U.S., students' expectations of college, belief systems, and perceptions of gender roles, occupation, and lifestyle choice. Despite the fact that immigrant students possess a different legal status, these factors are applicable to international students.

International students often experience culture shocks when they are transitioning from their home to the U.S., although many have learned of the U.S. culture prior to their arrival. Cultural differences, or a lack of knowledge of such differences, often lead international students to develop negative feelings, including embarrassment, intolerance, repugnance, isolation, homesickness, and depression (e.g., Erichsen \& Bolliger, 2011; Hamboyan \& Bryan, 1995; Szabo, Ward, \& Jose, 2016; Wang, Wei, Zhao, Chuang, \& Li, 2015). In turn, international students encounter more challenges when navigating U.S. higher education. In addition, international students' own cultural backgrounds contribute to their college adjustment and experiences. Students from cultures and languages that are similar to the host country tend to have a smoother transition, while those with more distinct cultural norms and 
languages are likely to face more barriers (Li \& Kaye, 1998; Leong, 2015; Yan \& Berliner, 2013).

\section{Chronosystem}

Finally, the chronosystem highlights the impact of time on this system of nested relationships; all of the sub-systems are situated in time and can change over time (Bronfenbrenner, 1992). Limited literature in academic advising focuses on the chronosystem, probably due to difficulties of collecting longitudinal data that can demonstrate changes and development of the sub-systems in the model. Nevertheless, at the student level, researchers in academic advising have noted the importance of understanding students' life transitions and individual development over time, such as prior educational and social environment, timing of coming to the U.S., duration in the U.S., and other life change events through time (Newell, 2015; Stebleton, 2011). Researchers have also developed advising approaches that highlight longitudinal and holistic perspectives. For example, Appreciative Advising, consists of six stages, encourages advisors to uncover students' life experiences in the past (Disarm \& Discover), identify their future goals (Dream), develop and implement plans to realize their goals (Design \& Deliver), and motivate them to dream about something bigger and better in the future (Don't Settle) (Bloom, Huston, \& He, 2008). Appreciative Advising has been recognized by numerous researchers as an important approach to bolster students' success in both four- and two-year environments (Hande, Christenbery, \& Phillippi, 2017; Huston \& Bloom, 2007; Zhang, 2016a).

\section{METHOD}

I employed a phenomenological research design to capture the complexity of experiences of both academic advisors and international community college students. This study was primarily conducted during the 2013-2014 academic year at a public, multi-campus community college in the state of Texas, one of the largest community college systems in the state. In Fall 2013, about 17,000 full-time students enrolled in the college and approximately 400 were international students. In this study, international students refer to those who study in the U.S. with an F-1 or J-1 student visa.

\section{Participant Selection}

Data collection involved semi-structured, open-ended interviews with both academic advisors and international advisees. Additional information was collected via email from international students with low English speaking proficiency. Using purposeful sampling technique, I selected academic advisors who had experiences in advising international students to participate in the study. I also extended the invitation to counselors who serve part of their time as academic advisors. Of the 49 invited, 17 academic advisors and three counselors volunteered to participate in the study, and they are all referred as academic advisors or advisors thereafter in this study. The advisors' ages ranged between the late $20 \mathrm{~s}$ and the late $50 \mathrm{~s}$, and four of them were male. One of the participants was self-identified as Latina, one Asian American, one biracial, two African Americans, and the rest of them were Caucasian. Their time serving in the current institution as an advisor varies from one to 16 years.

To recruit international students, I sent an email invitation directly to students who meet the following criteria: 1) enrolled in the community college with a F-1 or J-1 student visa in Fall 2013 or Spring 2014, 2) had studied at least a semester in the community college, and 3) 18 
years of age or older. I also contacted the advisors to encourage their advisees to participate in the study. Eventually, 11 students were interviewed in Spring 2014 and four more students participated in the study in Summer 2014. These students represented a broad spectrum of cultural and educational backgrounds. The students' ages ranged from 19 to 27, nine were female, and they were from six different countries, including China (mainland and Hong Kong), Congo, Jordan, Moldova, Vietnam, and Zimbabwe. At the time of the interview, the students had studied at the community college at least a semester and as many as six (including summer).

\section{Data Collection}

Data were drawn from detailed discussions with each participant lasting between 30 to 90 minutes. The interview protocol was developed to understand the experiences of advisors and international advisees. The interview questions for advisors focused on their overall advising experiences, and particularly, with international students. For international students, the questions were intended to explore their academic and social experiences in the community college and their interactions with academic advisors. The interviews were conducted in English. The questions were also emailed afterward to three of the student participants, who had low English proficiency, to respond to some of the questions in writing. I applied pseudonyms to each of the participants to protect their identity.

\section{Data Analysis}

All of the interviews were digitally recorded and transcribed verbatim. Before conducting any analysis, I sent the interview transcripts to the participants to validate the accuracy of the data, giving them opportunities to correct any errors or to provide any additional information (Lincoln \& Guba, 1985). Next, I examined the edited transcripts with the open-coding technique and developed coding matrices to identify thematic categories (Esterberg, 2002). In the first phase of the study, I analyzed the experiences of the advisers (Zhang, 2015) and the international students (Zhang, 2016b) separately.

In the current study, I synthesized the interviews from both advisors and students to offer a more holistic understanding of international community college student advisement. Once I have identified the themes, I debriefed with three colleagues who are experienced in conducting phenomenological research and knowledgeable in advising (Lincoln \& Guba, 1985). I related the findings to Bronfenbrenner's (1977, 1979, 1992) ecological model and reported them relevant to each sub-system in the model.

\section{FINDINGS}

Through a thorough analysis of the interviews of both advisors and international students, I organized the findings into five themes in response to the five systems in Bronfenbrenner's (1977, 1979, 1992) ecological framework (see Figure 1), including 1) advisor-advisee interactions in the microsystem, 2) influence of important others in the mesosystem, 3) policy influence in the exosystem, 4) cultural and language influence in the macrosystem, and 5) changes and transition in the chronosystem. Each of the themes is presented with sub-themes and supporting quotes from the advisors and international students.

Figure 1. Application of Bronfenbrenner's $(1977,1979,1992)$ ecological model in advising international community college students 


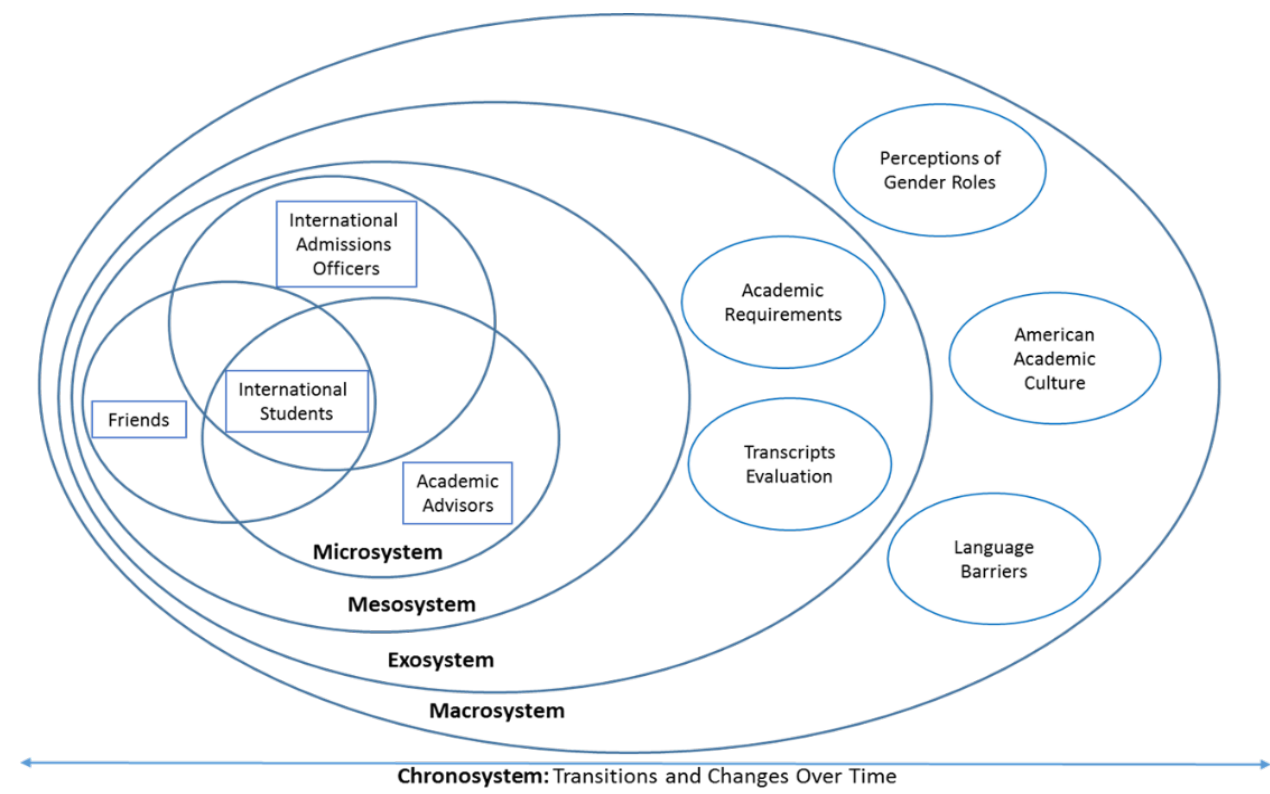

Figure 1. Application of Bronfenbrenner's (1977, 1979, 1992) ecological model in advising international community college students

\section{Advisor-Advisee Interactions in the Microsystem}

In Bronfenbrenner's $(1977,1979,1992)$ model, the microsystem is the first contextual level among all four layers of systems. For international community college students, there are multiple microsystems where they experience direct interactions with different groups of people, such as family, classmates, faculty, and staff on campus. Since this research study is centered on academic advising, this section focuses only on international students' interactions with their academic advisors. All of the student participants consented that academic advisors were important resources for their academic study and transition from home to the community college. They also agreed that they had a satisfying relationship with their advisors, despite that a few received inaccurate or delayed information. Echoing the students, the advisors reported positive experiences with international students and believed that such experiences enriched their cross-cultural understanding. The discussion of this theme consists of two major categories: 1) advisors as sources of support, and 2) working with and learning from international students

\section{Advisors as Sources of Support}

The interviews revealed that the international students were concerned about their academic plans, and relied on their academic advisors to develop and maintain an educational trajectory that best suits their goals. "They [academic advisors] are like an anchor for me," said David, an international Chinese student, "they help me stay on the right track." Similarly, Anthony, who was from Vietnam, indicated that all three academic advisors he had consulted were knowledgeable in course selection and one of them further encouraged him to transfer to a four-year university. The advisor provided him with detailed information about the transfer process and introduced him to one of his former advisees who had successfully transferred. 
In addition, the international students viewed their academic advisors as resources of support for the transition to the new environment. For instance, Olivia, a Vietnamese student, felt welcomed by all of her advisors. With the constant support, meeting with her current advisor made her feel like "a special person." Interactions with academic advisors also enhanced the international students' sense of belonging. Jack, from Hong Kong, appreciated the advisor's efforts in not only guiding him on his path to academic success, but also helping him adjust to the host city. For instance, the advisor shared with him places where he can shop for affordable Asian groceries. "She made me feel I'm at home," said Jack.

\section{Working with and Learning from International Students}

Conversations with the advisors showed similar evidence that, overall, there was a positive relationship between the advisors and the international students. Many advisors stated that they enjoyed working with these students and applied unique strategies to improve their advising experiences. For example, Jennifer lowered her speed of speaking to make conversations easier for advisees with limited English proficiency. Ruby suggested that advisors working with students with language barriers should "show more patience and respect" to them. In addition, the advisors viewed international students as an essential source to learn about other peoples, cultures, and languages. Ruby and Melanie reflected that, through interactions with international students, they became more mindful of various facets of their own culture and life.

\section{Influence of Important Others in the Mesosystem}

According to Bronfenbrenner (1977), the mesosystem is essentially a collection of microsystems. In addition to academic advisors, international students also frequently interacted with others on or off campus. Specifically, interactions with friends and international admissions officers substantially influenced international students' experiences in advising.

\section{Influence of Friends}

The international students seek information from not only academic advisors, but also their friends. In some circumstances, the international students felt more comfortable to take advice from their friends rather than advisors. For instance, Andrew, a Vietnamese student, stated,

I often like to talk to my friends, because... I think they also have the same problems and they have basically better understandings about my problems. They also talk to advisor [s], so, I just follow their advice. They [advisors] won't tell you what your experiences would be like taking certain courses, but my friends share information like that with me.

Additionally, the international students indicated that their friends heavily influenced their decisions on whether they should visit the advising office and which advisor they should consult with. For instance, Madison, from Zimbabwe, recalled that she normally checked with her friends or classmates first when she had questions about her academic work. If her problems remained unsolved, she would then make an appointment with an academic advisor. David signed up with Ms. Brown (pseudonym) because his friends from China recommended him to do so. "They had positive experiences with her, so I think I will have [a positive] one too." said David. 


\section{Influence of International Admissions Officers}

As one of the first personnel that most international students contact upon their arrival or even before their sojourn to the U.S., international admissions officers play a significant role in these students' admissions and transition. Different from their domestic counterparts, international students need to work with both international admissions officers and academic advisors to determine their academic plan. The interviews of this study revealed there was virtually no collaboration between the two divisions. For instance, Hannah, an international student from Moldova, expressed her confusion about the disconnection between the two offices, and questioned, "why can't they work together like in the same office?" Further, Madison added that going back and forth between the two offices was a "huge problem," because the admissions office is only located on the main campus and it is about 30 minutes away from the campus where she took all of her classes.

This disconnection was also recognized by the advisors. For instance, when asked if she communicated with the admissions office, Claire responded, "not at all. ...We don't at all. It's just kind of the students going back and forth between our two offices." Similarly, Samantha recalled that she had never met anybody in the international admissions department, and confessed that she even did not know the location of the office. For advisors who had contacted international admissions professionals, their experiences were limited to phone conversations. Lisa usually calls the admissions officers on behalf of her students to make sure that they receive accurate information before they leave her office.

I'll go ahead and use my phone and call them [international admissions staff] so that when they [international students] leave, they feel like, "I've accomplished something," instead of just leaving with a number to call to get it fixed.

Lisa was concerned that students would feel discouraged if their questions were not addressed properly, "if you were giving me the run-around with every corner, I wouldn't feel welcome."

Furthermore, the academic advisors expressed concerns about the students' experiences on campus and recommended that better communications between academic advising and international admissions should be fostered. Ashley suggested that they should visit the international admissions office to learn "what's all involved in intake of the international admissions students and then where do we carry them into advising."

\section{Policy Influence in the Exosystem}

Exosystem is the next level outward in the ecological system (Bronfenbrenner, 1977). In the exosystem, the interviews revealed that policies and academic requirements for international students made advising practice with these students more complex and could have a negative influence on the advising practice.

\section{Full-time Enrollment}

Due to the full-time enrollment policy, it was challenging for the advisors to provide appropriate guidance on academic planning for students in certain majors. For example, Samantha reported that it may look like students in medical programs are enrolled part-time, but the amount of time students need to dedicate to their study may be equivalent to or exceed the full-time requirement in other majors. She felt heartbroken for her international students because they were overwhelmed with the heavy course load. 
Students [in medical programs] would enroll in only 8 credit hours per semester and a full-time student is 12 . Well, those 8 credit hours are in no way a representation of an increment of time. They are in class Monday through Friday between the hours of 8:00 a.m. and 5:00 p.m. and doing 12-hour rotations in a hospital. As I said, the international admissions office told us "I'm sorry. You are 8 hours, so you've got to take two additional courses on top of this to meet the fulltime schedule."

The full-time enrollment policy may also create challenges for international students to maintain their legal status. Hannah, from Moldova, recalled a scenario where she was struggling to enroll in a new course because the original one was canceled at the last minute. Her legal academic standing would be jeopardized if she were not enrolled in the community college as a full-time student.

\section{Transcript Evaluation}

In the community college, international students who have earned credits from colleges or universities outside the U.S. need to have their transcripts evaluated through a third-party credential evaluation agency. As reported by the advisors, this policy adds another layer of intricacy to advising international students. Michael viewed transcript evaluation as the "most frustrating and confusing" practice for international students. Ashley commented that since there was no in-house evaluation assistance provided by the college, the transcript evaluation process could take four to six weeks. "Our hands are tied," Ashley further articulated that it was difficult for advisors to inform international students what courses to take before knowing what and how many credits would be transferred in.

\section{Cultural and Language Influence in the Macrosystem}

The macrosystem is the broadest level in the ecology system (Bronfenbrenner, 1977). The interviews with both advisors and international students revealed three main structures in the macrosystem, which influence and are influenced by the other layers of relationships surrounding advising international students in the community college. These structures are centered on differences in perceptions of gender roles, understanding of American academic culture, and language barriers.

\section{Perceptions of Gender Roles}

The academic advisors reported that international students from certain regions, such as the Middle East, tend to hold a different view on family, gender, and male-female relations when compared with domestic American students and international students from other parts of the world. This different view, which is largely attributed to the differences in religion and cultural norms, had a significant impact on the advisors' practice. For instance, Middle Eastern women students prefer to work with female advisors and were usually accompanied by a male family member when attending advising sessions. These male figures, such as a father, brother, or husband, normally dominate the conversation, despite the fact that the female students are the advisees. Ava recalled her difficulties in obtaining a thorough understanding of the needs of these female students,

We've had a lot of Middle Eastern women who are quiet... I am uncertain if the woman is if she's in agreement with what her spouse and myself are talking about and because it seems like her spouse is making the decisions for her. 
Echoing Ava, other advisors believe it is important to be directly connected with their advisees. For instance, Melanie encouraged her female students to come to speak to her alone, because she was afraid that these female students would not express their own thoughts in front of a male family member.

In addition, several female advisors felt challenged to advise male students from certain cultures because these students tend to perceive women as inferior to men. For instance, Samantha sensed rejection from some of her male advisees from Iran, India, or Israel, so that she asked her male colleagues to assure the students that the information provided by her was legitimate. Tara, with similar experiences, indicated that she would take on a more assertive attitude when advising some of her male students from the Caribbean.

\section{American Academic Culture}

The interviews with both academic advisors and international students suggest that many international students possess little knowledge of the U.S. learning environment. The academic advisors agreed that international students were at a disadvantage in their academic and social lives due to the lack of understanding of U.S. higher education, especially the community college system. For instance, Jennifer pointed out that many countries outside the U.S. do not have an academic system equivalent to the American community college. The transfer function, as a unique feature of the community college, is not well understood by many international students. Heather had to explain to her international advisees in detail about the basics of transfer, such as what means to transfer, how it works, and what they need to prepare. Similarly, Claire shared,

When I'm advising international students, I feel that I do go more into kind of "This is how college works." And a lotta times, international students will say, "I don't understand the college system here," or, "I don't know." And so I do go more into depth in my explanation sometimes.

The views of the international students were in conjunction with those of the advisors. These students felt that they had to overcome extra barriers when transitioning to the community college. Anthony, a Vietnamese student, confessed that he was not prepared to study in the U.S. when he first arrived on campus and did not know about the transfer process until his advisor introduced the concept to him.

In addition, the importance of academic advising was not fully comprehended by most of the international students at the beginning of their study in the community college. The interviews demonstrated a gap between the international students' perceptions of advising and the actual role it plays in their learning. Claire struggled to advise international students who have an unrealistic expectation for her,

"Well, can you bend the rules, so I don't have to take those classes?" or maybe classes are full and they've waited till the last minute, and they'll say, "Well, I have to have these many hours to stay here. You can just sign me up for that class." And it's like they seem sometimes do not understand that it's not even something I can do. The ability to maybe to do things or bend the rules if they can just talk me into it. And a lotta times - and we can't. I mean there are certain procedures that we have to follow. 


\section{Language Barrier}

Most of the student participants acknowledged language as a challenge in communicating with their academic advisors. For the participants from non-English speaking countries, low English proficiency prevents them from receiving effective advising. Anthony is such an example. Recalling his first advising session, Anthony did not receive sufficient guidance because he was not able to communicate clearly with his advisor. Consequently, Anthony went back to the advisor with more questions and checked with other advisors for clarification.

Echoing Anthony, the academic advisors who participated in the study shared similar concerns about language barriers. For instance, Allison believes that students' low English proficiency could seriously impair the quality of advising. She further shared a scenario where one of her advisees kept coming back to her with the same or similar questions due to ineffective communication. Working with these students, Ashley struggled to "convey the seriousness of something or the order of things," and Claire sometimes felt "helpless to know what to do to help a student that's having a hard time understanding." Facing the same obstacle, Samantha wished that she could have a thorough conversation with international students to better understand their needs and make sure that they are on the right path.

\section{Transition and Changes in the Chronosystem}

The last layer of the ecology system, chronosystem, emphasizes that all of the former subsystems are influenced by time, and both individuals and environments can change over time (Bronfenbrenner, 1992). Focusing on international students, this study reported findings related to the students' life transitions and the changing student demographics on campus, and how these changes affect advising practices.

\section{Students' Transition}

The advisors acknowledged that the international advisees were in a critical life transition and experienced more challenges than domestic students. They were also cognizant that the students' previous experiences in education and exposure to the U.S. culture could be a crucial ingredient in academic advising. For instance, Melanie indicated that understanding the international students' backgrounds and their life stories helped her advise these students. She also recommended that the academic advisors should "spend some time with the students to learn what they have done in the past, how they are transitioning from their home culture to here, and what their goals are for the future." Similarly, the international students felt better connected with the advisors when they were given opportunities to share their experiences of studying in their home country. In contrast, a lack of such opportunities could lead to disengagement in advising activities. For instance, Hannah, from Moldova, felt disconnected from her advisors, because she felt that they did not understand her past and what she had gone through.

\section{Changing Student Population}

The academic advisors, especially those who had served for a few years, acknowledged the change of the student population on campus. These advisors noticed that in the past few years an increasing number of international students came to visit them. Many indicated there was a need for additional resources to assist international students, but none of them received training or participated in any workshops focusing on serving this growing student population. The international students interviewed in this study offered similar suggestions. Emma, who was 
from Congo, indicated that the advising service was "good," but it "can be geared more towards the needs of the international students." She also recommended that the institution "should provide more help and make things easier" for international students.

\section{DISCUSSION AND IMPLICATIONS}

Taking Bronfenbrenner's (1977, 1979, 1992) ecological approach, I explored academic advising in a cross-cultural environment and provided a more holistic understanding of advising international community college students. This model could help academic advisors better assist not only the growing body of international students, but also the increasingly diversified domestic student population.

\section{Microsystem}

The international students appreciated their relationships with the advisors, and viewed their interactions as a key contributor to their academic and social adjustment in the community college. Since academic advisors are often the ones whom the students encounter first on campus, it is critical for the advisors to establish a meaningful relationship with the students (Drake, 2013; Vianden \& Barlow, 2015). To strengthen such a critical relationship and to propel international students' forward for their success in the community college, academic advisors could use the first meetings as opportunities to create a welcoming environment where international students feel comfortable raising questions. They could also participate in activities and events on campus to get to know more of their international advisees.

\section{Mesosystem}

The interviews with both international students and the advisors showed that, in addition to academic advisors, international students interacted with other individuals for guidance and information. These international students consulted with their friends with a similar cultural and language background and international admissions officers. The findings of this study confirmed Bronfenbrenner's $(1977,1979,1992)$ theory that the microsystems interact with each other. For instance, the international students' decisions on whether to see an advisor and which advisor they intended to see were influenced by their peers' suggestions. Peer advising is an important supplement to the formal advising provided by the advisors, as it can offer a student perspective on college life and academic study. However, peers' advice can be biased and misleading. Without receiving direct consultation from advisors, international students may not be aware of other possibilities and thus limit themselves to fewer options. Thus, academic advisors could develop advising strategies that incorporate peers' opinions but minimize potential negative effects on academic advising. For instance, academic advisors could offer group-advising that allows international students to discuss with their peers while exchanging ideas with the advisor.

According to the findings, there are limited direct communications between the international admissions officers and the academic advisors. As both professionals play important roles in international students' study and adjustment, academic advisors should collaborate with the international admissions officers to amplify their expertise to serve this growing student population. To facilitate such collaboration, professionals from both offices could meet regularly to keep the departments updated with the latest information and knowledge regarding international students. 


\section{Exosystem}

The findings of this study indicate that both students and academic advisors are challenged by international student regulations and policies. Understanding the details of the rules can significantly improve the quality of advising. It can also help advisors provide accurate information, and thus prevent international students from making unintentional mistakes that may jeopardize their student status. As discussed above, academic advisors can team up with international admissions officers and other student affairs professionals to keep abreast with policy changes. Community colleges may consider developing an online advising system that serves as a gatekeeper of international student requirements. The system could provide early warnings if any policies or rules are violated. It also gives access to students as well as advisors to view the information, so that the students are empowered in the advising process.

\section{Macrosystem}

The findings of the study confirm with previous research (i.e., Li \& Kaye, 1998; Leong, 2015; Reid\& Dixon, 2012; Yan \& Berliner, 2013) that cultural and language differences have an important impact on advising international students, and often, the differences create new challenges for both advisors and students. The findings suggest that international students are likely to have different perceptions and expectations of gender roles. To better serve advisees from various cultural backgrounds, academic advisors may consider incorporating multicultural approaches in the advising practice. There is ample evidence that advisors with higher cultural sensitivity and responsiveness have better interactions with international students (Rice et al., 2009; Zhang \& Dixon, 2001). Advisors could improve their cultural comprehension by listening empathically, as it is the first and foremost step in advising in situations of cultural difference (Mathis-Lawson, 2017). Academic advisors could also study the students' cultural backgrounds and former educational systems prior to meeting with the students, and increase awareness of their own biases and prejudices (Davis, 2011). To better prepare them for the cross-cultural transition, community colleges could offer international students an online orientation, as soon as they are admitted, to study the U.S. culture in general and the community college academic culture in specific.

As repeatedly mentioned in previous studies (Leong, 2015; Poyrazli \& Graham, 2007; Sato \& Hodge, 2009; Zhang, 2016c), international students' language proficiency is closely related to their college experience and academic performance. International students, especially those whose first language is not English, tend to experience more challenges in communicating with advisors and other important personnel on campus. This may suggest that academic advisors, if they do not speak the same language with their international advisees, need to be at least patient with the students and focus on the meaning, rather than the grammar, of the conversation (Nguyen, 2013). Academic advisors can rely on other tools and technology to facilitate the conversation, such as flowcharts, pictures, and online translators. For international students, before mastering English, they could record their meetings with advisors and listen to the conversation later as needed.

\section{Chronosystem}

The advisors who participated in the study acknowledged the increase in international enrollment and the changing demands of the students. They also expressed the need for training on how to advise international students. This may request not only the effort of academic advisors, but also the institutional commitment to promoting international student success. For 
instance, community colleges could develop workshops on cross-cultural communication and provide advisors with opportunities to learn best practices from other institutions.

In addition, the participating advisors recognized the importance of understanding international students' changes over time, including their history, current experience, and future goals. The advisors should transcend the traditional definition of "international students" and the stereotypes associated with it, and focus on learning students' backgrounds. Knowledge of international students' backgrounds could enhance advisors' understanding of the students' needs, and more importantly, their strengths and assets (He, 2009). Thus, advisors can gain a more holistic perspective and provide academic advising that capitalizes on students' capabilities and talents (He \& Huston, 2018).

\section{CONCLUSION}

Academic advisors are critical to student success as their roles and responsibilities have been evolving and expanding in the past few decades (Center for Community College Student Engagement [CCCSE], 2018). They do not only help students with academic-related questions, but also assist them with transition to college, direct them to other available resources on campus, and provide guidance on their future academic pursuit (CCCSE, 2018). By applying Bronfenbrenner's $(1977,1979,1992)$ ecological theoretical framework, this study provides meaningful insights into structures that directly or indirectly affect advising international students and interactions within and between different levels of the environment. This framework could provide a valuable lens for advisors to better understand the challenges of working with international students. It could also unveil forthcoming experiences for prospective international students.

As international students continue to select community colleges as their educational destination or stepping-stones to obtain a baccalaureate degree, it is not surprising that many academic advisors at community colleges are experiencing a new learning curve to provide effective advising to international students. Although the issues discussed in the current study are not the only ones existing in practice, this study represents a critical step forward in improving the quality of advising international students in community colleges. Future researchers could continue this line of inquiry and endeavor to make advising a true learning opportunity for international students.

\section{ACKNOWLEDGMENT}

The author gratefully acknowledge that this manuscript is based on work funded by a 2013 research grant from NACADA: The Global Community for Academic Advising.

\section{REFERENCES}

Bai, H., \& Pan, W. (2009). A multilevel approach to assessing the interaction effects on college student retention. Journal of College Student Retention: Research, Theory \& Practice, 11(2), 287-301.

Baloglu, M. (2000, August). Expectations of international students from counselling services. Paper presented at the Annual Conference on the American Psychological Association, Washington, DC. (ERIC Document, ED447372)

Bargerstock, C., \& McCarthy, K. (2012, May 22). Immigration basics: FAQ for academic advisors advising international students. NAFSA. Retrieved from https://www.nafsa.org/ findresources/Default.aspx?id=32981 
Bhochhibhoya, A., Dong, Y., \& Branscum, P. (2017). Sources of social support among international college students in the United States. Journal of International Students, 7(3), 671-686.

Bista, K. (2015). Roles of international student advisors: Literature and practice in American higher education. International Education, 44(2), 87-101.

Bloom, J. L., Hutson, B. L., \& He, D. Y. (2008). The appreciative advising revolution. Champaign, IL: Stipes Publishing Co.

Bronfenbrenner, U. (1977). Toward an experimental ecology of human development. American Psychologist, 32(7), 513-530.

Bronfenbrenner, U. (1979). The ecology of human development: Experiments by nature and design. Cambridge: Harvard University Press.

Bronfenbrenner, U. (1992). Ecological systems theory. In R. Vasta (Ed.), Annals of child development. Six theories of child development: revised formulations and current issues (pp. 187-249). London: Jessica Kingsley.

Burd, S. (2002, April 26). Bush may bar foreign students from "sensitive courses." The Chronicle of Higher Education. Retrieved from https://www.chronicle.com/article/Bush-May-Bar-ForeignStudents/21457

Cadieux, R. A., \& Wehrly, B. (1986). Advising and counseling the international student. New Directions for Student Services, 1986(36), 51-63.

Campbell, S. M., \& Nutt, C. L. (2008). Academic advising in the new global century: Supporting student engagement and learning outcomes achievement. Peer Review, 10(1), 4-7.

Center for Community College Student Engagement. (2018). Show me the way: The power of advising in community colleges. Austin, TX: The University of Texas at Austin, College of Education, Department of Educational Leadership and Policy, Program in Higher Education Leadership. Retrieved from http://www.ccsse.org/nr2018/Show_Me_The_Way.pdf

Charles, H., \& Stewart, M. A. (1991). Academic advising of international students. Journal of Multicultural Counseling and Development, 19(4), 173-181.

Davis, J. C. (2011). Intercultural sensitivity in foreign student advising: A quantitative analysis of ethnocentrism within the profession in the post-9/11 era. Saarbrücken, Germany: VDM Verlag Dr. Müller.

Drake, J. K. (2013). Advising as teaching and the advisor as teacher in theory and in practice. In J. K. Drake, P. Jordan, \& M. A. Miller (Eds.), Academic advising approaches: Strategies that teach students to make the most of college (pp. 17-32). San Francisco, CA: Jossey-Bass.

Erichsen, E., \& Bolliger, D. (2011). Towards understanding international graduate student isolation in traditional and online environments. Educational Technology Research and Development, 59, 309-326. doi:10.1007/s11423-010-9161-6

Esterberg, K. (2002). Qualitative methods in social research. New York, NY: McGraw-Hill.

Fischer, K. (2017, September, 6). Many colleges see a drop in international students, Chronicle survey finds. The Chronicle of Higher Education. Retrieved from https://www.chronicle. com/article/Many-Colleges-See-a-Drop-in/241109

Gillespie, G. M. (2012, March 2). Guide to advising international students about academic integrity. The Mentor: An Academic Advising Journal. Retrieved from https://dus.psu.edu /mentor/2012/03/guide-to-advising-international-students-about-academic-integrity/

Hamboyan, H., \& Bryan, A. K. (1995). International students: Culture shock can affect the health of students from abroad. Canadian Family Physician, 41, 1713-1716.

Hande, K., Christenbery, T., \& Phillippi, J. (2017). Appreciative advising: An innovative approach to advising doctor of nursing practice students. Nurse Educator, 42(6), E1-E3.

He, Y. (2009). Strength-based mentoring in pre-service teacher education: a literature review. Mentoring \& Tutoring: Partnership in Learning, 17(3), 263-275.

He, Y., \& Hutson, B. (2018). Exploring and leveraging Chinese international students' strengths for success. Journal of International Students, 8(1), 87-108. 
Hunter, M. S., \& White, E. R. (2004). Could fixing academic advising fix higher education? About Campus, 9, 20-25. Hutson, B. L. (2010). The impact of an appreciative advising-based university studies course on college student first-year experience. Journal of Applied Research in Higher Education, 2(1), 4-13.

Hutson, B. L., \& Bloom, J. L. (2007). The impact of appreciative advising on student success. E-Source for College Transitions, 5(1), 4-5.

Institute of International Education (IIE). (2016). International student enrollments by institutional type, 2014/15-2015/16. Open Doors Report on International Educational Exchange. Retrieved from https://www.iie.org/Research-and-Insights/Open-Doors/Data/International-

Students/Enrollment/Enrollment-by-Institutional-Type/2015---2016

Institute of International Education (IIE). (2017a). Project Atlas quick look. Retrieved from https://www.iie.org/Research-and-Insights/Project-Atlas/Explore-Data/Current-Infographics

Institute of International Education (IIE). (2017b). International student enrollments trends, 1948/492016/17. Open Doors Report on International Educational Exchange. Retrieved from https://www.iie.org/Research-and-Insights/Open-Doors/Data/International-Students/Enrollment

Kim, Y. K., Collins, C. S., Rennick, L. A., \& Edens, D. (2017). College experiences and outcomes among international undergraduate students at research universities in the United States: A comparison to their domestic peers. Journal of International Students, 7(2), 395-420.

Kim, Y. K., Edens, D., Iorio, M. F., Curtis, C. J., \& Romero, E. (2015). Cognitive skills development among international students at research universities in the United States. Journal of International Students, 5(4), 526-540.

Kless, S. H. (2004, October 8). We threaten national security by discouraging the best and brightest students from abroad. The Chronicle of Higher Education. Retrieved from http://justice.law.stetson.edu/excellence/Highered/archives/2005/DiscouragingBestBrightest.pdf

Langhinrichsen-Rohling, J., Snarr, J. D., Slep, A. M. S., Heyman, R. E., \& Foran, H. M. (2011). Risk for suicidal ideation in the U.S. Air Force: An ecological perspective. Journal of Consulting and Clinical Psychology, 79(5), 600-612.

Lau, J., Garza, T., \& Garcia, H. (2018). International students in community colleges: On-campus services used and its affect on sense of belonging. Community College Journal of Research and Practice. doi: 10.1080/10668926.2017. 1419891

Lau, J., \& Ng, K. M. (2014). Conceptualizing the counseling training environment using Bronfenbrenner's ecological theory. International Journal for the Advancement of Counselling, 36(4), 423-439.

Leong, F. T. L., \& Sedlacek, W. E. (1986). A comparison of international and U.S. students' preferences for help sources. Journal of College Student Personnel, 27, 426-430

Leong, P. (2015). Coming to America: Assessing the patterns of acculturation, friendship formation, and the academic experiences of international students at a US college. Journal of International Students, 5(4), 459-474.

Li, R. Y., \& Kaye, M. (1998). Understanding overseas students' concerns and problems. Journal of Higher Education Policy and Management 20(1), 41-50.

Lincoln, Y. S., \& Guba, E. G. (1985). Naturalistic inquiry. Beverly Hills, CA: SAGE.

Mamiseishvili, K. (2012). International student persistence in US postsecondary institutions. Higher Education, 64(1), 1-17.

Mathis-Lawson, S. (2017). Academic advising, servant leadership, and academic locus of control: A Study of student success in an historically Black college and university population (Doctoral dissertation, North Carolina Agricultural and Technical State University).

McLeod, J., \& Shanahan, M. (1993). Poverty, parenting, and children's mental health. American Sociological Review, 58, 351-366.

Mori, S. (2000). Addressing the mental health concerns of international students. Journal of Counseling and Development, 78, 137-144. 
Nazarenko, N. M. (2006). Educational and cultural experiences of Latin American and Asian women students at one of the U.S. Southwest border universities (Doctoral dissertation, New Mexico State University). Retrieved from https://search.proquest.com/docview/305276869/fulltext PDF/C9A8756DBDFD4967PQ/1?accountid=7117

Newell, E. M. (2015). International student-athlete adjustment issues: Advising recommendations for effective transitions. The Journal of the National Academic Advising Association, 35(2), 36-47.

Nguyen, H. M. (2013). Faculty advisors' experiences with international graduate students. Journal of International Students, 3(2), 102-116.

Paat, Y. F. (2013). Working with immigrant children and their families: An application of Bronfenbrenner's ecological systems theory. Journal of Human Behavior in the Social Environment, 23(8), 954-966.Renn, K. A. (2003). Understanding the identities of mixed-race college students through a developmental ecology lens. Journal of College Student Development, 44(3), 383-403.

Poyrazli, S., \& Graham, K. (2007). Barriers to adjustment: Needs of international students within a semiurban campus community. Journal of Instructional Psychology, 34, 28- 45.

Reid, L. M., \& Dixon, A. L. (2012). The counseling supervision needs of international students in U.S. institutions of higher education: A culturally-sensitive supervision model for counselor educators. Journal for International Counselor Education, 4, 29-41.

Rice, K. G., Choi, C. C., Zhang, Y., Villegas, J., Ye, H. J., Anderson, D., Nesic, A., \& Bigler, A. (2009). International student perspectives on graduate advising relationships. Journal of Counseling Psychology, 56, 376-391.

Rose-Redwood, C., \& Rose-Redwood, R. (2017). Rethinking the politics of the international student experience in the age of Trump. Journal of International Students, 7(3), I-IX.

Sato, T., \& Hodge, S. R. (2009). Asian international doctoral students' experiences at two American universities: Assimilation, accommodation, and resistance. Journal of Diversity in Higher Education, 2(3), 136-148.

Schwebel, D. C., \& Bresausek, C. M. (2007). The role of context in risk for pediatric injury: Influences from the home and child care environments. Merrill-Palmer Quarterly, 53(1), 105-130.

Stebleton, M. J. (2011). Understanding immigrant college students: Applying a developmental ecology framework to the practice of academic advising. NACADA Journal, 31(1), 42-54.

Swecker, H. K., Fifolt, M., \& Searby, L. (2013). Academic advising and first-generation college students: A quantitative study on student retention. NACADA Journal, 33(1), 46-53.

Szabo, A., Ward, C., \& Jose, P. E. (2016). Uprooting stress, coping, and anxiety: A longitudinal study of international students. International Journal of stress management, 23(2), 190-208.

Tas, M. (2013). International students: Challenges of adjustment to university life in the US. International Journal of Education, 5(3), 1-10. doi:10.5296/ije.v5i3.3481

Vianden, J., \& Barlow, P. J. (2015). Strengthen the bond: Relationships between academic advising quality and undergraduate student loyalty. The Journal of the National Academic Advising Association, 35(2), 15-27.

Wang, K. T., Wei, M., Zhao, R., Chuang, C.-C., \& Li, F. (2015). The cross-cultural loss scale: development and psychometric evaluation. Psychological Assessment, 27, 42-53

Yan, K., \& Berliner, D. C. (2013). Chinese international students' personal and sociocultural stressors in the United States. Journal of College Student Development, 54(1), 62-84.

Zhai, L. (2004). Studying international students: Adjustment issues and social support. Journal of International Agricultural and Extension Education, 11(1), 97-104.

Zhang, N., \& Dixon, D. N. (2001). Multiculturally responsive counseling: Effects on Asian students' ratings of counselors. Journal of Multicultural Counseling and Development, 29(4), 253-262.

Zhang, Y. L. (2015). Intercultural communication competence: Advising international students in a Texas community college. The National Academic Association (NACADA) Journal, 35(2), 4859. 
Zhang, Y. L. (2016a). Appreciative advising with international students in American community colleges. In R. L. Raby \& E. J. Valeau (Eds.), International education at community colleges: Themes, practices, and case studies (pp. 93-109). Palgrave Macmillan.

Zhang, Y. L. (2016b). An overlooked population in community college: International students' (in)validation experiences with Academic Advising. Community College Review, 44(2), 1-18.

Zhang, Y. L. (2016c). International students in transition: Voices of Chinese doctoral students in a U.S. research university. Journal of International Students, 6(1), 175-194.

Zhang, Y. L., \& Dinh, T. (2017). Understanding intercultural communication competence of academic advisors in the college of engineering. The NACADA Journal, 37(2), 33-43.

YI LEAF ZHANG, Ph.D., is Associate Professor in the Department of Educational Leadership and Policy Studies at the University of Texas at Arlington. Her major research interests lie in the area of community colleges as a gateway to STEM education, transfer students' educational pathways, and international education in four- and two-year institutions. Email: Lyzhang@uta.edu

Manuscript submitted: March 13, 2018

Manuscript revised: June 6, 2018

Accepted for publication: May 31, 2018 